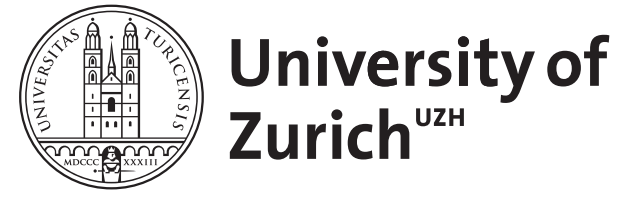

\title{
The lottery contest is a best-response potential game
}

\author{
Ewerhart, Christian
}

\begin{abstract}
It is shown that the image-player lottery contest admits a best-response potential (Voorneveld 2000, Economics Letters). This is true also when the contest technology reflects the possibility of a draw. The result implies, in particular, the existence of a non-trivial two-player zero-sum game that is best-response equivalent to a game with identical payoff functions.
\end{abstract}

DOI: https://doi.org/10.1016/j.econlet.2017.03.030

Posted at the Zurich Open Repository and Archive, University of Zurich

ZORA URL: https://doi.org/10.5167/uzh-136449

Journal Article

Accepted Version

Originally published at:

Ewerhart, Christian (2017). The lottery contest is a best-response potential game. Economics Letters, 155:168-171.

DOI: https://doi.org/10.1016/j.econlet.2017.03.030 


\section{Accepted Manuscript}

The lottery contest is a best-response potential game

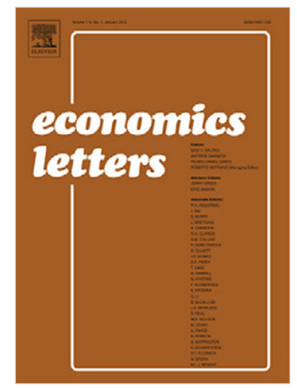

PII:

S0165-1765(17)30132-5

DOI: $\quad$ http://dx.doi.org/10.1016/j.econlet.2017.03.030

Reference: $\quad$ ECOLET 7565

To appear in: $\quad$ Economics Letters

Received date: 2 February 2017

Revised date: 10 March 2017

Accepted date : 23 March 2017

Please cite this article as: Ewerhart, C., The lottery contest is a best-response potential game.

Economics Letters (2017), http://dx.doi.org/10.1016/j.econlet.2017.03.030

This is a PDF file of an unedited manuscript that has been accepted for publication. As a service to our customers we are providing this early version of the manuscript. The manuscript will undergo copyediting, typesetting, and review of the resulting proof before it is published in its final form. Please note that during the production process errors may be discovered which could affect the content, and all legal disclaimers that apply to the journal pertain. 


\section{${ }^{\star}$ Highlights (for review)}

\section{Highlights}

> The n-player lottery contest is shown to admit a best-response potential.

> This holds likewise for contest technologies that reflect the possibility of a draw.

> In particular, a non-trivial two-player zero-sum game may admit a best-response potential. 


\title{
The Lottery Contest is a Best-Response Potential Game*
}

\author{
Christian Ewerhart**
}

March 10, 2017

\begin{abstract}
It is shown that the $n$-player lottery contest admits a best-response potential (Voorneveld, 2000, Economics Letters). This is true also when the contest technology reflects the possibility of a draw. The result implies, in particular, the existence of a nontrivial two-player zero-sum game that is best-response equivalent to a game with identical payoff functions.
\end{abstract}

Keywords. Potential games $\cdot$ Tullock contest $\cdot$ Best-response equivalence $\cdot$ Zero-sum games JEL-Codes. C62, C72, D72

*) An anonymous referee provided helpful comments. For useful conversations, I thank Drew Fudenberg, Nikolai Kukushkin, and Arsen Palestini.

**) Department of Economics, University of Zurich, Schönberggasse 1, CH-8001 Zurich, Switzerland; christian.ewerhart@econ.uzh.ch. 


\section{Introduction}

Potential games are interesting because they allow conclusions not only regarding existence and uniqueness of Nash equilibrium, but also regarding the outcome of dynamic and boundedly rational adjustment processes. Since Monderer and Shapley's (1996) seminal contribution, the literature has produced increasingly flexible variants of the initial concepts. One such generalization has led to the notion of a best-response potential (Voorneveld, 2000; Kukushkin, 2004; Dubey et al., 2006; Uno, 2007, 2011; Park, 2015). According to the definition, a game with continuous strategy spaces admits a best-response potential if there is a game with identical payoff functions that is best-response equivalent (henceforth BRequivalent, etc.) to the original game, i.e., that has the same BR-correspondence, mapping any profile of pure strategies to a set of pure strategy profiles, as the original game.

This paper has two parts. In the first, we show that the $n$-player lottery contest admits a BR-potential. This holds true regardless of whether the contest allocates the prize with probability one (Haavelmo, 1954; Tullock, 1975; Bell et al., 1975; Baron, 1994) or there is a probability of a draw (Loury, 1979; Dasgupta and Nti, 1998; Blavatskyy, 2010; Jia, 2012). ${ }^{1}$ In the second part of the paper, we exploit the strategic equivalence between contests and zero-sum games, ${ }^{2}$ so as to derive potentially interesting implications of our result. In particular, it is shown that a non-trivial two-player zero-sum game may be BR-equivalent to a game with identical payoff functions.

The lottery contest and its natural generalizations have found widespread application in economics and political theory (Konrad, 2009). It corresponds to a Cournot game with isoelastic inverse demand and constant marginal costs. Deschamps (1975) proved convergence of fictitious play in a two-player Cournot oligopoly with strictly declining BR-functions. Thorlund-Peterson (1990) extended this result to an arbitrary number of firms. An exact potential exists for the Cournot game with linear demand (Slade, 1994). More generally, sufficient conditions for the existence of a BR-potential have been found for aggregative games that allow monotone BR-selections (Huang, 2002; Dubey et al., 2006; Jensen, 2010). However, all these methods do not apply to the lottery contest whose BR-function is not

\footnotetext{
${ }^{1}$ Like this paper, Dasgupta and Nti (1998) allow for both cases.

${ }^{2}$ By strategic equivalence, we mean vNM-equivalence (Morris and Ui, 2004), i.e., for each player, the payoff function in one game is equal to a positive constant times the payoff function in the other game, plus a term that depends only on the opponents' strategies. The strategic equivalence between contests and zero-sum games is implicit in Moulin and Vial (1978). Applications include Pavlov (2013), Ewerhart and Valkanova (2016), and Hwang and Rey-Bellet (2017).
} 
monotone (Dixit, 1987). Also more recent examples of BR-potential games (Dragone et al., 2012; Bourlès et al., 2015) do not cover the case of the lottery contest.

\section{The lottery contest admits a BR-potential}

In the lottery contest $G^{a}$, with noise parameter $a \geq 0$, common valuation $V>0$, and $n \geq 2$ players, each player $i \in\{1, \ldots, n\}$ simultaneously and independently chooses an effort $x_{i} \geq 0$, and subsequently receives a payoff of

$$
u_{i}^{a}\left(x_{1}, \ldots, x_{n}\right)=\left\{\begin{array}{cc}
\frac{x_{i}}{a+\bar{x}} V-x_{i} & \text { if } a+\bar{x}>0 \\
V / n & \text { if } a+\bar{x}=0,
\end{array}\right.
$$

where $\bar{x}=x_{1}+\ldots+x_{n}$ denotes aggregate effort. The game $G^{a}$ is known to possess a unique pure-strategy Nash equilibrium that is necessarily symmetric (Dasgupta and Nti, 1998). ${ }^{3}$

An $n$-person game $G=\left(X_{1}, \ldots, X_{n}, u_{1}, \ldots, u_{n}\right)$ with strategy spaces $X_{i}$ and payoff functions $u_{i}: X \equiv X_{1} \times \ldots \times X_{n} \rightarrow \mathbb{R}$ for players $i=1, \ldots, n$ is called a BR-potential game (Voorneveld, 2000) if there exists a function $P: X \rightarrow \mathbb{R}$ such that

$$
\underset{x_{i} \in X_{i}}{\arg \max } P\left(x_{i}, x_{-i}\right)=\underset{x_{i} \in X_{i}}{\arg \max } u_{i}\left(x_{i}, x_{-i}\right)
$$

for any $i=1, \ldots, n$ and any $x_{-i}=\left(x_{1}, \ldots, x_{i-1}, x_{i+1}, \ldots, x_{n}\right) \in X_{-i} \equiv X_{1} \times \ldots \times X_{i-1} \times X_{i+1} \times$ $\ldots \times X_{n}$.

The following observation has, to the author's knowledge, not been documented in the literature. ${ }^{4}$

Proposition 1. For any $a \geq 0$, the $n$-player lottery contest is a BR-potential game.

Proof. Consider first the case $a>0$. We claim that, in this case,

$$
P^{a}\left(x_{1}, \ldots, x_{n}\right)=\left\{a \bar{x}+\sum_{j<k} x_{j} x_{k}\right\} V-\frac{1}{3}(a+\bar{x})^{3}
$$

is a BR-potential for $G^{a}$. Indeed, differentiating (3), we find

$$
\frac{\partial P^{a}\left(x_{i}, x_{-i}\right)}{\partial x_{i}}=\left(a+\bar{x}_{-i}\right) V-(a+\bar{x})^{2},
$$

\footnotetext{
${ }^{3}$ For $a=0$, Dasgupta and Nti (1998) assume a different tie-breaking rule, viz. $u_{i}^{0}(0, \ldots, 0)=0$ for $i=1, \ldots, n$. The BR-correspondence is the same, however.

${ }^{4}$ Cf., e.g., Chowdhury and Sheremata (2015) and González-Sánchez and Hernández-Lerma (2016).
} 
where $\bar{x}_{-i}=x_{1}+\ldots+x_{i-1}+x_{i+1}+\ldots+x_{n}$. Moreover,

$$
\frac{\partial^{2} P^{a}\left(x_{i}, x_{-i}\right)}{\partial x_{i}^{2}}=(-2) \cdot(a+\bar{x})<0,
$$

i.e., the problem of maximizing $P^{a}\left(., x_{-i}\right)$ subject to $x_{i} \geq 0$ is strictly concave. The unique solution $x_{i}^{*} \equiv x_{i}^{*}\left(x_{-i}, a\right)$ is given by

$$
x_{i}^{*}=\left\{\begin{array}{cl}
\sqrt{\left(a+\bar{x}_{-i}\right) V}-a-\bar{x}_{-i} & \text { if } \bar{x}_{-i} \leq V-a \\
0 & \text { if } \bar{x}_{-i}>V-a .
\end{array}\right.
$$

But this is just player $i$ 's best-response function in $G^{a}$. Hence,

$$
\underset{x_{i} \geq 0}{\arg \max } P^{a}\left(x_{i}, x_{-i}\right)=\underset{x_{i} \geq 0}{\arg \max } u_{i}^{a}\left(x_{i}, x_{-i}\right),
$$

as claimed.

Consider next the case $a=0$. Denote by $\pi(x)$ the number of nonzero entries of the vector $x=\left(x_{1}, \ldots, x_{n}\right)$. We claim that

$$
P^{0}\left(x_{1}, \ldots, x_{n}\right)=\left\{\begin{array}{cl}
\left(\sum_{j<k} x_{j} x_{k}\right) V-\frac{1}{3} \bar{x}^{3} & \text { if } \pi\left(x_{1}, \ldots, x_{n}\right) \geq 2 \\
-\frac{1}{3} x_{j} V^{2} & \text { if } \pi\left(x_{1}, \ldots, x_{n}\right)=1 \text { and } x_{j}>0 \\
-\frac{1}{3} \frac{n-1}{n} V^{3} & \text { if } \pi\left(x_{1}, \ldots, x_{n}\right)=0
\end{array}\right.
$$

is a BR-potential for $G^{0}$. To see this, suppose first that $x_{-i}$ has at least two nonzero entries. Then, certainly $\pi\left(x_{1}, \ldots, x_{n}\right) \geq 2$, so that from (8),

$$
P^{0}\left(x_{1}, \ldots, x_{n}\right)=\left(\sum_{j<k} x_{j} x_{k}\right) V-\frac{1}{3} \bar{x}^{3} .
$$

Moreover, $u_{i}^{0}\left(., x_{-i}\right)$ is differentiable, so that in straightforward extension of the case $a>0$ considered above,

$$
\underset{x_{i} \geq 0}{\arg \max } P^{0}\left(x_{i}, x_{-i}\right)=\underset{x_{i} \geq 0}{\arg \max } u_{i}^{0}\left(x_{i}, x_{-i}\right) .
$$

Suppose next that $x_{-i}$ has precisely one nonzero entry $x_{j}>0$. Then, $\pi\left(x_{1}, \ldots, x_{n}\right)=2$ if $x_{i}>0$, and $\pi\left(x_{1}, \ldots, x_{n}\right)=1$ if $x_{i}=0$. Hence, using (8) another time,

$$
P^{0}\left(x_{1}, \ldots, x_{n}\right)=\left\{\begin{array}{cc}
x_{i} x_{j} V-\frac{1}{3}\left(x_{i}+x_{j}\right)^{3} & \text { if } x_{i}>0 \\
-\frac{1}{3} x_{j} V^{2} & \text { if } x_{i}=0 .
\end{array}\right.
$$

We have to show that the problem of maximizing $P^{0}\left(., x_{-i}\right)$ subject to $x_{i} \geq 0$ has the unique solution that is given by player $i$ 's best-response function in $G^{0}$, i.e., by $x_{i}^{*}=\sqrt{x_{j} V}-x_{j}$ 
if $x_{j} \leq V$ and by $x_{i}^{*}=0$ if $x_{j}>V$. From the above, it clearly suffices to verify that the problem $\max _{x_{i} \geq 0} P^{0}\left(x_{i}, x_{-i}\right)$ has an interior solution if and only if $x_{j}<V$. But indeed, using (11), one can easily check that for $x_{j}>0$,

$$
\lim _{\substack{x_{i} \rightarrow 0 \\ x_{i}>0}} P^{0}\left(x_{i}, x_{-i}\right)=-\frac{1}{3} x_{j}^{3}>-\frac{1}{3} x_{j} V^{2}=P^{0}\left(0, x_{-i}\right)
$$

if and only if $x_{j}<V$, as illustrated in Figure 1.

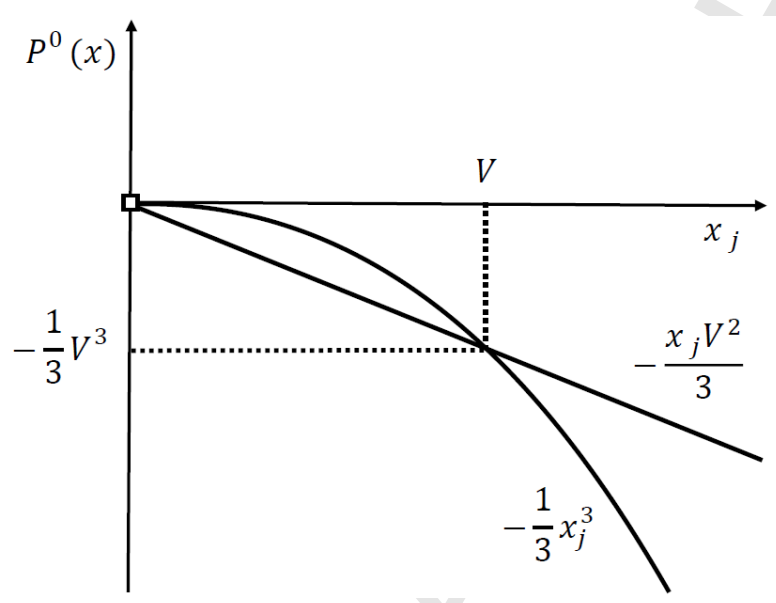

Figure 1. Constructing a BR-potential in the case $a=0$.

Finally, suppose that all entries of $x_{-i}$ are zero. Then, again from (8), $P^{0}\left(x_{i}, x_{-i}\right)=-\frac{1}{3} x_{i} V^{2}$ if $x_{i}>0$, but $P^{0}\left(0, x_{-i}\right)<0$, so that $\underset{x_{i} \in X_{i}}{\arg \max } P^{0}\left(x_{i}, x_{-i}\right)=\varnothing$. Similarly, $u_{i}^{0}\left(x_{i}, x_{-i}\right)=$ $V-x_{i}$ if $x_{i}>0$, but $u_{i}^{0}\left(0, x_{-i}\right)=V / n$, so that $\underset{x_{i} \in X_{i}}{\arg \max } u_{i}^{0}\left(x_{i}, x_{-i}\right)=\varnothing$. Thus, $P^{0}$ is indeed a BR-potential for $G^{0}$.

\section{Discussion}

Note that $G^{a}$ does not allow an exact potential for any $a \geq 0$. Indeed, for $i \neq j$,

$$
\frac{\partial^{2} u_{i}^{a}(x)}{\partial x_{i} \partial x_{j}}=\frac{\left(x_{i}-x_{j}\right)-\left(\sum_{k \neq i, j} x_{k}\right)-a}{(a+\bar{x})^{3}} V
$$

is not symmetric with respect to $i$ and $j$, as required by Monderer and Shapley's (1996) necessary condition. Along similar lines, it can be seen that the lottery contest is not a weighted potential game either.

For $a \geq V$, the function $u_{i}^{a}\left(\cdot, x_{-i}\right)$ is strictly declining for any $x_{-i}$ and $i$, and therefore, $P^{a}$ is actually an ordinal potential for $G^{a}$. However, $P^{a}$ is not even a generalized ordinal 
potential when $a<V$. Indeed, for $x_{i}=\varepsilon>0$ small enough, $x_{i}^{\prime}=V-a$, and $\bar{x}_{-i}=0$,

$$
u_{i}^{a}\left(x_{i}, x_{-i}\right)-u_{i}^{a}\left(x_{i}^{\prime}, x_{-i}\right)=\left(\frac{\varepsilon}{a+\varepsilon} V-\varepsilon\right)-\left(\frac{V-a}{a+(V-a)} V-(V-a)\right)>0,
$$

whereas, from (3) and (8),

$$
P^{a}\left(x_{i}, x_{-i}\right)-P^{a}\left(x_{i}^{\prime}, x_{-i}\right)=\varepsilon\left\{a(V-a-\varepsilon)-\frac{\varepsilon^{2}}{3}\right\}-\frac{(V-a)^{3}}{3}<0,
$$

in conflict with the definition. ${ }^{5}$

Park (2015) argued that, if preferences are complete but the BR-set is empty, the BRpotential should generate the same preferences over strategies as the payoff function. To check this condition, note that for $x_{-i}=0$,

$$
P^{0}\left(x_{i}, x_{-i}\right)=\left\{\begin{array}{cc}
-\frac{1}{3} x_{i} V^{2} & \text { if } x_{i}>0 \\
-\frac{1}{3} \frac{n-1}{n} V^{3} & \text { if } x_{i}=0 .
\end{array}\right.
$$

Thus, $P^{0}$ induces a preference for lower strategies among positive strategies $x_{i}>0$, and an indifference between $x_{i}=0$ and $x_{i}=\frac{n-1}{n} V$. This is likewise true for preferences reflecting player $i$ 's payoffs when $x_{-i}=0$,

$$
u_{i}^{0}\left(x_{i}, x_{-i}\right)=\left\{\begin{array}{cl}
V-x_{i} & \text { if } x_{i}>0 \\
V / n & \text { if } x_{i}=0 .
\end{array}\right.
$$

Thus, $P^{0}$ satisfies Park's condition.

Proposition 1 extends to any convex combination between a purely random allocation and the lottery contest (Haavelmo, 1954; Baron, 1994). The same is true for Amegashie's (2006) contest with minimum efforts.

\section{Implications}

This section presents two implications of Proposition 1.

An $n$-player game $G$ will be called $n-1$ multilateral if for any $i=1, \ldots, n$, there exist functions $h_{i j}: X_{-j} \rightarrow \mathbb{R}$ for $j \in\{1, \ldots, n\}$, such that $u_{i}(x)=\sum_{j=1}^{n} h_{i j}\left(x_{-j}\right)$. Any zero-sum equivalent potential $n$-player game is necessarily equivalent to an $n-1$ multilateral game (Brânzei et al., 2003; Hwang and Rey-Bellet, 2017). As the following result shows, this need not be so for a zero-sum equivalent BR-potential game.

\footnotetext{
${ }^{5}$ This leaves, of course, the theoretical possibility that another function might be a (generalized) ordinal potential for $G^{a}$ when $a<V$.
} 
Proposition 2. For any $n \geq 2$, there exists a zero-sum equivalent BR-potential $n$-player game that is not equivalent to an $n-1$ multilateral game.

Proof. Recall that $G^{0}$ is strategically a zero-sum game. ${ }^{6}$ To see that $G^{0}$ is not $n-1$ multilateral, note that

$$
\frac{\partial^{n-1} u_{i}^{a}\left(x_{i}, x_{-i}\right)}{\partial x_{1} \ldots \partial x_{i-1} \partial x_{i+1} \ldots \partial x_{n}}=(-1)^{n-1}(n-1) ! \frac{x_{i}}{\left(x_{i}+\bar{x}_{-i}\right)^{n}}
$$

depends nontrivially on $x_{i}$, which is impossible for an $n-1$ multilateral game.

Call a two-player game trivial if each player's BR-correspondence is constant. For $n=2$, the statement of Proposition 2 may be strengthened as follows.

Corollary 1. There exists a non-trivial two-person zero-sum equivalent BR-potential game.

Hwang and Rey-Bellet (2017) have shown that, for $n \geq 3$, the $n$-player Cournot game with linear demand, which admits an exact potential, is zero-sum equivalent. This is not true for $n=2$, however, so that Corollary 1 may indeed be of interest.

\section{References}

Amegashie, J.A. (2006), A contest success function with a tractable noise parameter, Public Choice 126, 135-144.

Baron, D.P. (1994), Electoral competition with informed and uninformed voters, American Political Science Review 88, 33-47.

Bell, D.E., Keeney, R.L., Little, J.D. (1975), A market share theorem, Journal of Marketing Research 12, 136-141.

Blavatskyy, P. (2010), Contest success function with the possibility of a draw: Axiomatization, Journal of Mathematical Economics 46, 267-276.

Bourlès, R., Bramoullé, Y., Perez-Richet, E. (2015), Altruism in Networks, mimeo.

Brânzei, R., Mallozzi, L., Tijs, S. (2003), Supermodular games and potential games, Journal of Mathematical Economics 39, 39-49.

Chowdhury, S., Sheremata, R. (2015), Strategically equivalent contests, Theory and Decision 78, 587-601.

\footnotetext{
${ }^{6}$ For a direct proof, consider the $n$-player game $G$ with payoffs $u_{i}(x)=u_{i}^{0}(x)-\frac{V}{n}+x_{i+1}$, where $x_{n+1}=x_{1}$. Since $G$ is zero-sum, this proves the claim.
} 
Dasgupta, A., Nti, K.O. (1998), Designing an optimal contest, European Journal of Political Economy 14, 587-603.

Deschamps, R. (1975), An algorithm of game theory applied to the duopoly problem, European Economic Review 6, 187-194.

Dixit, A. (1987), Strategic behavior in contests, American Economic Review 77, 891-898.

Dragone, D., Lambertini, L., Palestini, A. (2012), Static and dynamic best-response potential functions for the non-linear Cournot game, Optimization 61, 1283-1293.

Dubey, P., Haimanko, O., Zapechelnyuk, A. (2006), Strategic complements and substitutes, and potential games, Games and Economic Behavior 54, 77-94.

Ewerhart, C., Valkanova, K. (2016), Fictitious play in networks, University of Zurich.

González-Sánchez, D., Hernández-Lerma, O. (2016), A survey of static and dynamic potential games, Science China Mathematics 59, 2075-2102.

Haavelmo, T. (1954), A Study in the Theory of Economic Evolution, North-Holland, Amsterdam.

Huang, Z. (2002), Fictitious play in games with a continuum of strategies, $\mathrm{PhD}$ thesis, Stony Brook.

Hwang, S.-H., Rey-Bellet, L. (2017), Strategic decomposition of normal form games: Potential games and zero-sum games, mimeo.

Jensen, M.K. (2010), Aggregative games and best-reply potentials, Economic Theory 43, $45-66$.

Jia, H. (2012), Contests with the probability of a draw: A stochastic foundation, Economic Record 88, 391-406.

Konrad, K.A. (2009), Strategy and Dynamics in Contests, Oxford University Press.

Kukushkin, N.S. (2004), Best response dynamics in finite games with additive aggregation, Games and Economic Behavior 48, 94-110.

Loury, G.C. (1979), Market structure and innovation, Quarterly Journal of Economics 93, 395-410.

Monderer, D., Shapley, L. (1996), Potential games, Games and Economic Behavior 14, 124-143.

Morris, S., Ui, T. (2004), Best response equivalence, Games and Economic Behavior 49, 260-287.

Moulin, H., Vial, J-P. (1978), Strategically zero-sum games: The class of games whose completely mixed equilibria cannot be improved upon, International Journal of Game Theory 7, 201-221. 
Pavlov, G. (2013), Correlated equilibria and communication equilibria in all-pay auctions, University of Western Ontario.

Park, J. (2015), Potential games with incomplete preferences, Journal of Mathematical Economics 61, 58-66.

Slade, M. (1994), What does an oligopoly maximize? Journal of Industrial Economics 42, 45-61.

Thorlund-Petersen, L. (1990), Iterative computation of Cournot equilibrium, Games and Economic Behavior 2, 61-75.

Tullock, G. (1975), On the efficient organization of trials, Kyklos 28, 745-762.

Uno, H. (2007), Nested potential games, Economic Bulletin 3, 1-8.

Uno, H. (2011), Strategic complementarities and nested potential games, Journal of Mathematical Economics 47, 728-732.

Voorneveld, M. (2000), Best-response potential games, Economics Letters 66, 289-295. 